\title{
Morphology of migration: Associations between wing, and bill morphology and migration in kingbirds (Tyrannus)
}

Short Title: Ecomorphology of migration in kingbirds (Tyrannus)

Authors \& Affiliations

Maggie P. MacPherson ${ }^{1,2^{*}}$, Alex E. Jahn ${ }^{3,4}$, Nicholas A. Mason ${ }^{2}$

${ }^{1}$ Department of Ecology and Evolutionary Biology, Tulane University, New Orleans, LA 70118

${ }^{2}$ Louisiana State University Museum of Natural Sciences, Louisiana State University, Baton Rouge, LA 70803

${ }^{3}$ Departamento de Zoologia, Universidade Estadual Paulista, Av. 24a No. 1515, Rio Claro, Brazil

${ }^{4}$ Environmental Resilience Institute, Indiana University, 717 E 8th St., Bloomington, IN 47408

"Corresponding author: Maggie P. MacPherson, E-mail: maggie.macpherson@gmail.com 


\section{Abstract}

2 Morphology is closely linked to locomotion and diet in animals. In animals that undertake long-

3 distance migrations, limb-morphology is under selection to maximize mobility and minimize

4 energy expenditure. Migratory behaviors also interact with diet, such that migratory animals tend

5 to be dietary generalists, while sedentary taxa tend to be dietary specialists. Despite a

6 hypothesized link between migration status and morphology, phylogenetic comparative studies

7 have yielded conflicting findings. We tested for evolutionary associations between migratory

8 status and limb and bill morphology across kingbirds, a pan-American genus of birds with

9 migratory, partially migratory, and sedentary taxa. Migratory kingbirds had longer wings, in

10 agreement with expectations if selection favors improved aerodynamics for long-distance

11 migration. We also found an association between migratory status and bill shape, such that

12 more migratory taxa had wider, deeper, and shorter bills compared to sedentary taxa. However,

13 there was no difference in intraspecific morphological variation among migrants, partial

14 migrants, and residents, suggesting that dietary specialization has evolved independently of

15 migration strategy. The evolutionary links between migration, diet, and morphology in kingbirds

16 uncovered here further strengthen ecomorphological associations that underlie long-distance

17 seasonal movements in animals.

18 Keywords: ecomorphology, flycatcher, migration, movement ecology, natural selection, partial

19 migration, Tyrannidae

\section{Introduction}

22 Animal movement is linked to morphology at various taxonomic scales. At a macroevolutionary

23 scale, streamlined or aerodynamic body shapes have been associated with the evolution of 
24 long-distance migration in fish (Chapman et al., 2015), insects (Johansson, Söderquist, \&

25 Bokma, 2009), and birds (Fiedler, 2005). Within species, migratory distance has also been

26 associated with streamlined body shapes in fish (e.g., Crossin et al., 2004) and aerodynamic

27 shapes in birds (Voelker, 2001; Minias et al., 2015; Vágási et al., 2016). While certain taxa with

28 long-distance movements exhibit strong selection for energy-efficient body shapes, this is not

29 universal (Mulvihill \& Chandler, 1990; Mönkkönen, 1995; Wang \& Clarke, 2015). Thus, there is

30 a persistent need to expand the taxonomic breadth of studies linking migration and morphology

31 to better understand which lineages exhibit migration-morphology associations, and why these

32 associations vary among taxa.

Morphology is also shaped by foraging strategies. For example, dietary niche is associated with head and body shape in fish (Knudsen et al., 2011; Závorka et al., 2020), birds

35 (Felice et al., 2019), and mammals (Swanson, Oliveros, \& Esselstyn, 2019). Additionally, phenotypic plasticity is expected in dietary generalists, as shown in comparative commongarden experiments in stickleback minnows (Svanbäck \& Schluter, 2012). In populations recently released from interspecific competition, such as island colonizers (Wilson, 1961; Clegg \& Owens, 2002), phenotypic plasticity is thought to support increased morphological variation to limit intraspecific competition (i.e., 'niche variation hypothesis', Van Valen, 1965). Migratory

41 lineages of dietary generalists may have strong preferences for food resources that are easiest

42 to access (Sherry, 1984; Levey \& Stiles, 1992; Bell, 2011) or that are superabundant (Moreau,

43 1952; Morse, 1971; Willis, 1974). In contrast, sedentary individuals may mitigate intra- and

44 interspecific competition by seeking temporally stable food resources in microhabitats that are

45 buffered from environmental fluctuation (e.g., temperature fluctuations; Bell, 2011).

46 Comparisons across avian species (Levey \& Stiles, 1992) and families (Chesser \& Levey, 1998)

47 have shown migratory taxa that forage on seasonally variable resources tend to exhibit more 
morphological variation, presumably associated with opportunistic foraging across a wider dietary breadth among or within individuals (Bell, 2011). phylogenetic comparative framework with comprehensive inter- and intraspecific sampling. Studies comparing migratory to sedentary birds support that long-distance migration favors

53 longer (Rayner, 1988; Wiedenfeld, 1991; Pérez-Tris \& Tellería, 2001; Förschler \& Bairlein,

54 2011; Tellería et al., 2013), and more pointed (Carvalho Provinciato, Araújo, \& Jahn, 2018;

55 Gómez-Bahamón et al., 2020b) wings for increased aerodynamics. Hypotheses that link bill

56 morphology and migratory status are less well-studied, but hinge on differences in diet that

57 covary with migratory status (Bell, 2011; but see Cox, 1968; Herrera, 1978; Leisler, 1990).

58 Sedentary insectivorous taxa often have longer bills, presumably to improve closing speed for

59 capturing highly mobile prey (Leisler, 1990). In contrast, migratory taxa may have shorter bills

60 for capturing slow-moving prey like caterpillars to feed young during the breeding season and

61 small, abundant arthropods during winter (Thiollay, 1988; Leisler, 1990). Furthermore, studies

62 on bill size in relation to foraging strategies disagree, such that both narrow and wide bills are

63 associated with generalist diets (Tellería \& Carbonell, 1999; Tellería et al., 2013), and bill size

64 differs between isolated specialist populations of the same species (Alonso et al., 2020). species did not account for their shared evolutionary history (Cox, 1968, 1985; Leisler, 1990).

67 Boyle and Conway (2007) advanced this approach by performing phylogenetically independent

68 contrasts to address selective pressures for the evolution of migration between species (see

69 also Gómez et al., 2016; Vágási et al., 2016). However, the literature on the role of migratory 70 status in shaping morphological phenotypes in birds draws predominantly from comparisons

71 among distantly related taxa (e.g., Rappole's 1995; critique of Herrera 1978). Thus, detailed

72 comparisons among taxa that differ in migratory status within a modern phylogenetic 
73 comparative framework are necessary for a more comprehensive test of how migration is

74 associated with morphology at different taxonomic scales (e.g., Bolnick et al., 2007).

We used phylogenetic comparative methods to test for ecomorphological associations in wing and bill morphology among migratory, partially migratory, and sedentary kingbirds (Tyrannus; Fitzpatrick et al., 2004). Kingbirds are flycatchers (Tyrannidae) with considerable variation in migration status and morphology within and among species, as well as a rich body of literature linking ecology and morphology (Fitzpatrick \& Schauensee, 1980; Fitzpatrick, 1981; Sherry, 1984; Fitzpatrick, 1985; Cintra, 1997; Fitzpatrick et al., 2004; Gabriel \& Pizo, 2005;

81 Carvalho Provinciato et al., 2018; Gómez-Bahamón et al., 2020b). As aerodynamic theory

82 predicts that longer, more pointed wings and shorter tails are more efficient for long-distance

83 migratory flights (Norberg, 1995; Pennycuick, 2008), we expected migratory taxa to have longer

84 and more pointed wings compared to sedentary taxa (Kipp, 1942, 1958; Winkler \& Leisler, 1992; Mönkkönen, 1995 and references therein; Lockwood, Swaddle, \& Rayner, 1998). Tails of long-distance migrants should also be shorter than more sedentary individuals to reduce drag during long-distance flights (Rayner, 1988; Norberg, 1990; Winkler \& Leisler, 1992; Förschler \& Bairlein, 2011). However, tails are targets of sexual selection (Winquist \& Lemon, 1994; Mobley,

89 2002), and tail lengths are often unassociated with migration strategy (e.g., Voelker, 2001; Neto et al., 2013). Within-population variation in flight capability could be associated with migration

91 (Fernández \& Lank, 2007) or foraging ecology (Hromada \& Tryjanowski, 2003), so we also

92 tested whether more migratory taxa have more variable wing morphology compared to less 93 migratory taxa.

95 size and shape is typically related to broad dietary categories in birds (e.g., $>50 \%$ insectivorous, 96 granivorous, frugivorous etc.; e.g., Reaney et al., 2020). We therefore predicted that there would 97 be no relationship between migratory status and bill size because all kingbirds are primarily 
98 insectivorous. Additionally, migration may impart an 'ecological release' associated with the

99 evolution of a more variable, opportunistic diet (Bell, 2011). We thus predicted that more

100 migratory taxa will have higher coefficients of variation in bill morphology compared to less

101 migratory taxa.

102

103 Methods

\section{Phylogeny construction}

105 We extracted the clade of 15 kingbird taxa from the Harvey et al. (2020) suboscine phylogeny to

106 construct a kingbird phylogeny that includes 28 operational taxonomic units (OTUs). Harvey et

107 al. (2020) included all species (13/13) but only $15 \%$ of the subspecific diversity (3/20). We

108 therefore added $T$. savana taxa following phylogenetic relationships and branch lengths

109 estimated by Gómez-Bahamón (2020a). The remaining subspecies were added as polytomies

110 assuming a most recent common ancestor (MRCA) of 0.5 million years from members of their

111 species group (Figure 1A). To test the sensitivity of analyses to this assumption, we tested a

112 range of different dates for the MRCA for the added subspecies, which did not change the

113 results (Supplementary Information 1). 

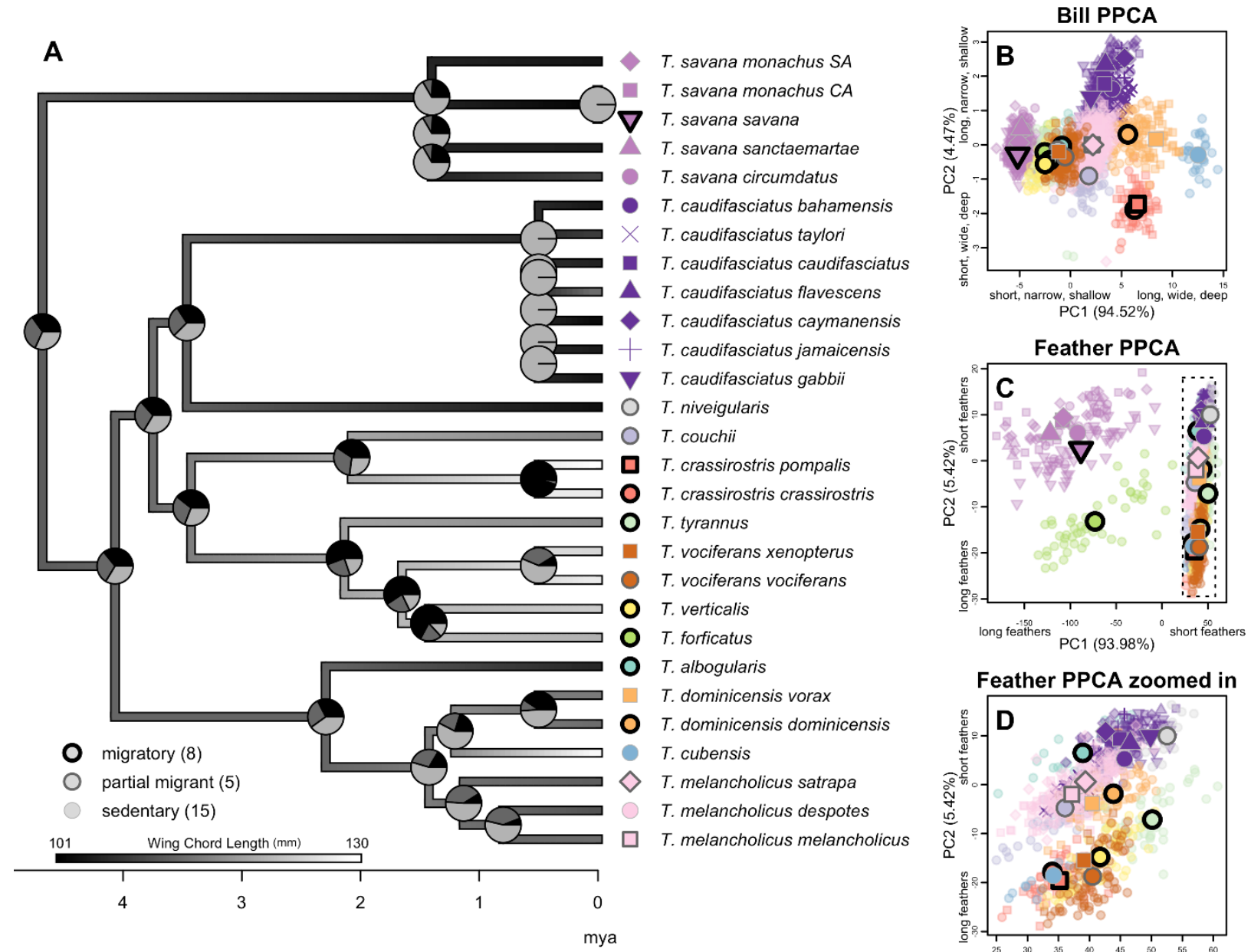

\section{Feather PPCA zoomed in}
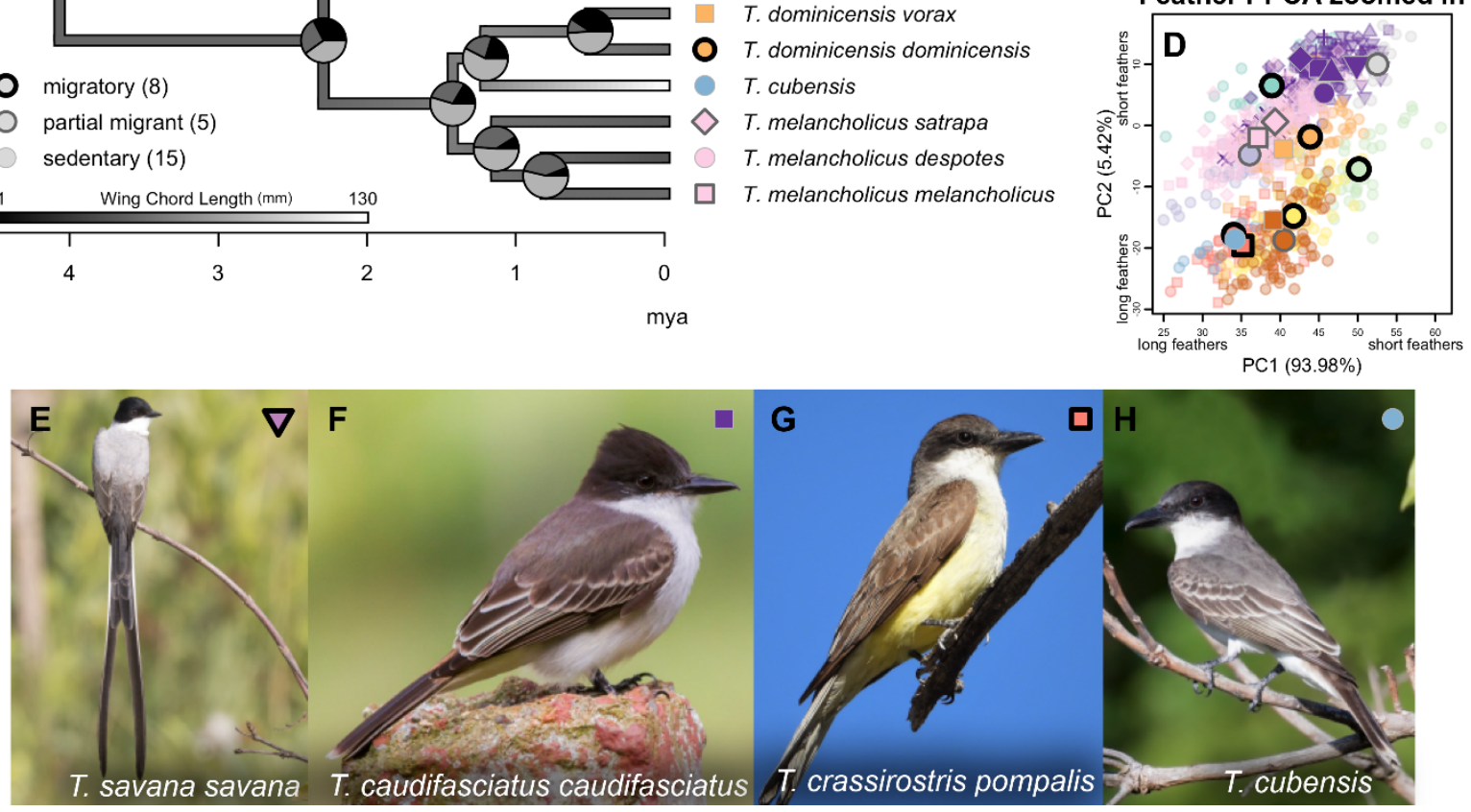

Figure 1. Ancestral state reconstruction of migration ecology category and wing chord length, as well as ordination of 28 kingbird OTUs for bill (length, width, depth) and feather (wing chord length, tail length, and Kipp's distance). A) Kingbird phylogeny showing ancestral state reconstruction of migration ecology strategy (pie charts at each node), and wing chord length (branch greyscale). B-D) PPCA plots showing individuals color-coded to species (identified at the tip labels of the phylogeny), shape-coded to subspecies, and their status as migratory, partially migratory, or sedentary is distinguished via the shape outline. Pie charts for each node in the phylogeny show the ancestral state reconstruction of migration type. E-H) photos of representative kingbird taxa with corresponding color- and shape-coded points in the top right of 
124

each photo. Taxa are as follows: E) Tyrannus savana savana (photo credit: Rodrigo Conte), F) Tyrannus caudifasciatus caudifasciatus (photo credit: Yeray Seminario / Whitehawk), G) Tyrannus crassirostris pompalis (photo credit: Martin Molina), and H) Tyrannus cubensis (photo credit: Dubi Shapiro).

\section{Morphological measurements}

We measured bill length, width, and depth at the distal end of the nares. We also measured unflattened wing chord length, Kipp's distance (a measure of wing pointedness: the distance between the tip of the first secondary feather to the tip of the longest primary feather; Kipp, 1942, 1958; Baldwin et al., 2010), tail length, and tarsus length on 2108 study skins from across the ranges of each species and subspecies (28 operational taxonomic units (OTUs);

Figure 1A; Table S1.1). MM measured 2008 specimens, and identified all individuals to the lowest level of taxonomic identification (using Clements et al., 2019) and classified each individual as migratory, partially migratory, or sedentary (sensu Fitzpatrick et al., 2004). Partially migratory taxa are those in which individuals vary in migratory tendency (Boyle, 2008). JIGA (see Acknowledgements) measured 100 specimens to improve sampling of some taxa. Bill and tail measurements were taken twice and were confirmed to be within one mm of one another. Both right and left wing chords and tarsus lengths were measured and averaged. Measurements by JIGA were only taken once. We measured tail length as the longest rectrix to the nearest $0.1 \mathrm{~cm}$ (Pyle et al., 1997). For most measurements, we used a Mitutoyo brand IP 67 digital calipers (part number 573-271) with a range of up to $15.24 \mathrm{~cm}$, with $0.00127 \mathrm{~cm}$ resolution. For tails longer than $15.24 \mathrm{~cm}$, we used a $30.48 \mathrm{~cm}$ stainless steel ruler placed between the two middle rectrices. When tails were longer than $30.48 \mathrm{~cm}$ photos were taken of the tails above a $0.64 \times 0.64 \mathrm{~cm}$ square grid with the calipers measuring to their extent and ImageJ was used to calculate the full tail length (Supporting Information 2). We then averaged measurements across individuals within each OTU for downstream analyses. To test 
associations between migratory strategy and intraspecific morphological variation, we also

151 calculated the coefficient of variation (mean/standard deviation) for each character and each

152 taxon. This provides a scaled measure of variance for each character and allows testing

153 whether migratory strategies differ in the amount of intraspecific variation.

We tested whether accounting for age (juvenile versus adult) and sex (female versus male) classes improved linear models explaining morphological measurements among taxa. We

156 did this using the mulTree function of the mulTree package (Guillerme \& Healy, 2020) in R,

157 which assesses intraspecific variation while accounting for phylogenetic relatedness (e.g.,

158 Nations et al., 2019). We found that including age class improved model fit for all characters

159 except tarsus length and including sex class improved model fit for all characters except bill

160 length and tarsus length (Supporting Information 1). We subsequently omitted juveniles from our

161 analyses, but presented the results of both sexes combined in the main text because our results

162 did not differ when analyzing sexes independently (Supporting Information 3).

\section{Phylogenetic Principal Components Analysis}

165 We conducted a phylogenetic principal component analysis (PPCA) for bill measurements using

166 the phyl.pca function from the phytools package (Revell, 2009) because this gives information

167 on bill volume and shape that is not reflected in individual bill measurements (Table 1). Bill

168 PPCA scores were included in the following phylogenetic analysis of variance (see next

169 section). PPCA was also conducted for sexes separately (Supporting Information 3).

171 Table 1. Results of phylogenetic principal component analysis (PPCA) of bill measurements.

172 Percent variance explained by each eigenvector is in brackets for each principal component. 


\begin{tabular}{lccc} 
Loadings & Bill PPC1 (94.52\%) & \multicolumn{2}{c}{ lambda } \\
Bill length & 0.99 & 0.14 & 0.95 \\
Bill width & 0.93 & -0.33 \\
Bill depth & 0.94 & -0.27
\end{tabular}

174 Phylogenetic Analysis of Variance

175 We compared morphology between migratory, partially migratory, and sedentary taxa via a 176 phylogenetic analysis of variance (Garland et al., 1993) with the phyIANOVA function in the 177 phytools package (Revell, 2012). As differences in body size can account for much of the 178 variation among species (Albrecht, Gelvin, \& Hartman, 1993; McCoy et al., 2006; Revell, 2009; 179 Berner, 2011), we extracted phylogenetic residuals (Revell, 2009) for each dependent variable 180 (bill length, bill width, bill depth, wing chord, Kipp's distance, and tail length) with tarsus length 181 as an approximation of body size and the independent variable. We opted to use tarsus instead 182 of mass to adjust for body size (Rising \& Somers, 1989; Senar \& Pascual, 1997) because mass 183 can change seasonally (particularly in migratory birds; Lindström \& Piersma, 1993) and also 184 varies by sex in some kingbirds (e.g., T. melancholicus, Jahn et al., 2010; T. savana, Carvalho 185 Provinciato et al., 2018; T. tyrannus, Murphy, 2007). To additionally support this decision, we 186 used the mulTree function of the mulTree package to test whether tarsus length had the highest 187 correlation among measurements while accounting for phylogeny, finding that tarsus length the 188 highest correlation with body mass among all variables for the individuals that had mass data 189 (Supporting Information 1). We then conducted a phylogenetic ANOVA for each character using 190 the residual values (with 1000 replicates) and reported mean P-values for pairwise, post-hoc 191 comparisons of mean values and coefficients of variation between migration categories. As 192 such, we conducted 51 tests of statistical significance, which raises the issue of multiple 
193 hypothesis testing (Shaffer, 1995). Opinions differ on whether or not to adjust P-values when

194 testing multiple hypotheses (Curran-Everett, 2000) and the 0.05 conventional threshold is

195 ultimately arbitrary (Wasserstein, Schirm, \& Lazar, 2019). Nonetheless, we report both

196 uncorrected P-values and Bonferroni-corrected P-values ( $n=3$ tests for each set of pairwise

197 comparisons of means or coefficients of variation). We also performed ancestral state

198 reconstructions of wing chord length with the contMap function in the phytools package (Revell,

199 2012) and of migratory status with the fit.mle function in the diversitree package (FitzJohn,

200 2012). All statistical analyses were performed using program $R$ version 4.0.3 (R Core Team,

$2012020)$.

203 Results

204 The mean values for each morphometric character +/- standard deviation for all adults in each

205 OTU are reported in Table S1.1. We found that migratory taxa had longer wing chords (Figure

206 2F, Table 2) and pointier wings than sedentary taxa (Figure 2D, Table 2). However, we found no

207 association between migratory status and coefficients of variation in bill morphology (Figure 2G-

208 I, Table 2). In agreement with our prediction, we found no relationship between migratory status

209 and bill length, width, depth, or bill PPC1 (Figure 2A-C, Figure 3A, Table 2). However, migratory

210 taxa had shorter, wider, and deeper bills (bill PPC2) compared to sedentary taxa, which had

211 longer, shallower, and more narrow bills (Figure 3B, Table 2). 

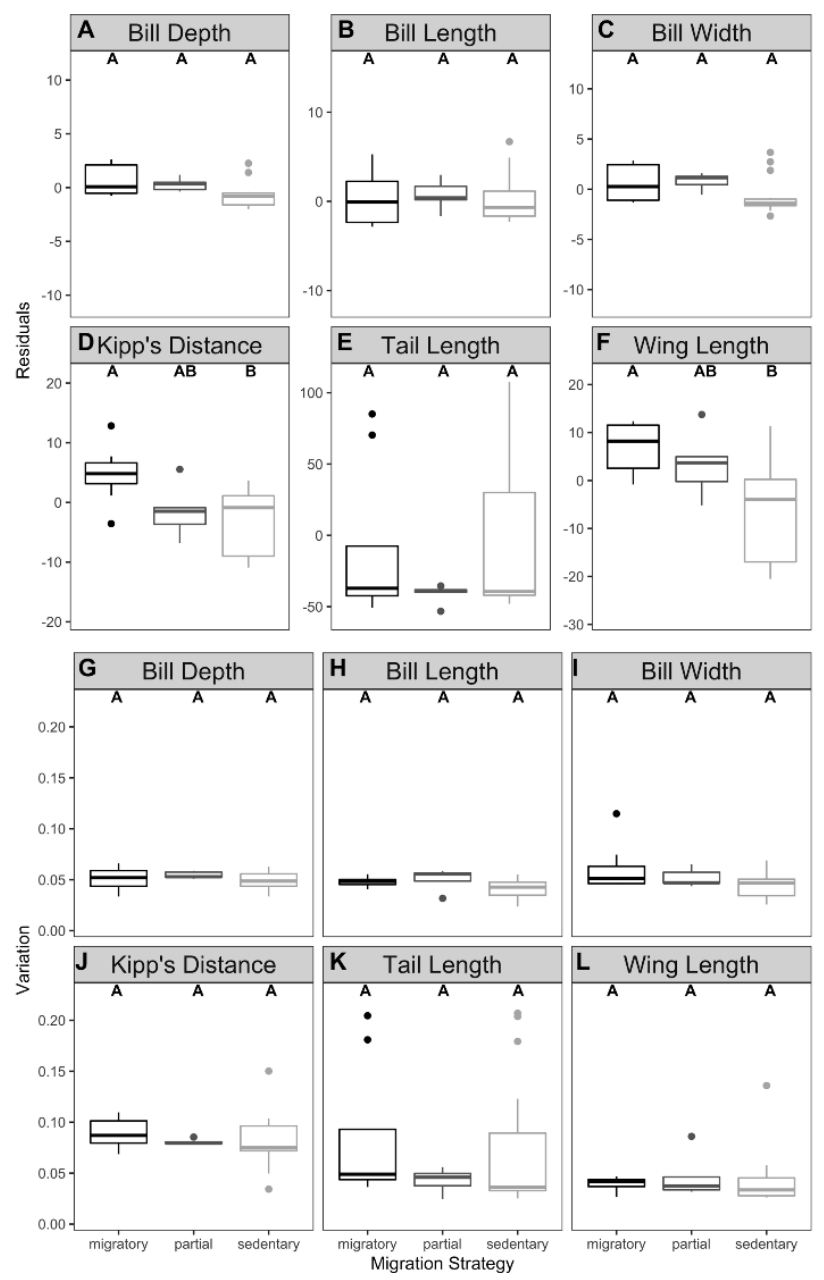

213 Figure 2. Phylogenetic ANOVA results comparing residuals of bill and feather morphometrics

221 Table 2. T and $\mathrm{P}$ values from phylogenetic ANOVA analysis of adult Tyrannus flycatchers.

222 Values shown in brackets are $P$ values with Bonferroni adjustment $(n=3)$ to account for

223 multiple hypothesis testing. Significant results are in bold. Model F and $\operatorname{Pr}(>F)$ values can be

224 found in Table S1.4.

225 


\begin{tabular}{|c|c|c|c|c|c|c|}
\hline & & $P(\operatorname{adj} . p)$ & $\mathrm{T}$ & $P(\operatorname{adj} . p)$ & $\mathrm{T}$ & $P(\operatorname{adj} . p)$ \\
\hline Bill length & 0.32 & $0.73(1.00)$ & 0.06 & $0.96(1.00)$ & 0.30 & $0.82(1.00)$ \\
\hline CV Bill length & 0.39 & $0.72(1.00)$ & 1.90 & $0.23(0.66)$ & 2.04 & $0.15(0.39)$ \\
\hline Bill width & 0.20 & $0.82(1.00)$ & 1.68 & $0.30(0.86)$ & 1.65 & $0.24(0.74)$ \\
\hline CV Bill width & 1.01 & $0.29(0.99)$ & 2.49 & $0.10(0.33)$ & 1.00 & $0.49(1.00)$ \\
\hline Bill depth & 0.50 & $0.60(1.00)$ & 2.17 & $0.17(0.49)$ & 1.29 & $0.40(1.00)$ \\
\hline CV Bill depth & 0.74 & $0.44(1.00)$ & 0.34 & $0.85(1.00)$ & 1.10 & $0.45(1.00)$ \\
\hline Bill PC1 (size) & 0.07 & $0.94(1.00)$ & 0.62 & $0.70(1.00)$ & 0.45 & $0.74(1.00)$ \\
\hline $\begin{array}{l}\text { CV Bill PC1 } \\
\text { (size) }\end{array}$ & 0.03 & $0.99(1.00)$ & 0.073 & $0.96(1.00)$ & 0.096 & $0.95(1.00)$ \\
\hline $\begin{array}{l}\text { Bill PC2 } \\
\text { (shape) }\end{array}$ & 0.64 & $0.53(1.00)$ & 3.91 & $0.01(0.03)$ & 2.60 & $0.06(0.18)$ \\
\hline $\begin{array}{l}\text { CV Bill PC2 } \\
\text { (shape) }\end{array}$ & 0.19 & $0.85(1.00)$ & 1.32 & $0.40(1.00)$ & 0.91 & $0.50(1.00)$ \\
\hline Kipp's distance & 2.11 & $0.05(0.11)$ & 3.73 & $0.02(0.04)$ & 0.83 & $0.57(1.00)$ \\
\hline $\begin{array}{l}\text { CV Kipp's } \\
\text { distance }\end{array}$ & 0.71 & $0.43(1.00)$ & 0.79 & $0.62(1.00)$ & 0.12 & $0.94(1.00)$ \\
\hline $\begin{array}{l}\text { Wing chord } \\
\text { length }\end{array}$ & 0.71 & $0.48(1.00)$ & 3.78 & $0.02(0.03)$ & 2.42 & $0.09(0.20)$ \\
\hline $\begin{array}{l}\text { CV Wing chord } \\
\text { length }\end{array}$ & 0.56 & $0.54(1.00)$ & 0.28 & $0.87(1.00)$ & 0.39 & $0.78(1.00)$ \\
\hline Tail length & 0.93 & $0.32(1.00)$ & 0.34 & $0.84(1.00)$ & 1.32 & $0.35(1.00)$ \\
\hline CV Tail length & 1.15 & $0.23(0.76)$ & 0.35 & $0.83(1.00)$ & 0.98 & $0.49(1.00)$ \\
\hline $\begin{array}{l}\text { CV Tarsus } \\
\text { length }\end{array}$ & 0.29 & $0.78(1.00)$ & 2.81 & $0.06(0.16)$ & 2.71 & $0.04(0.16)$ \\
\hline
\end{tabular}



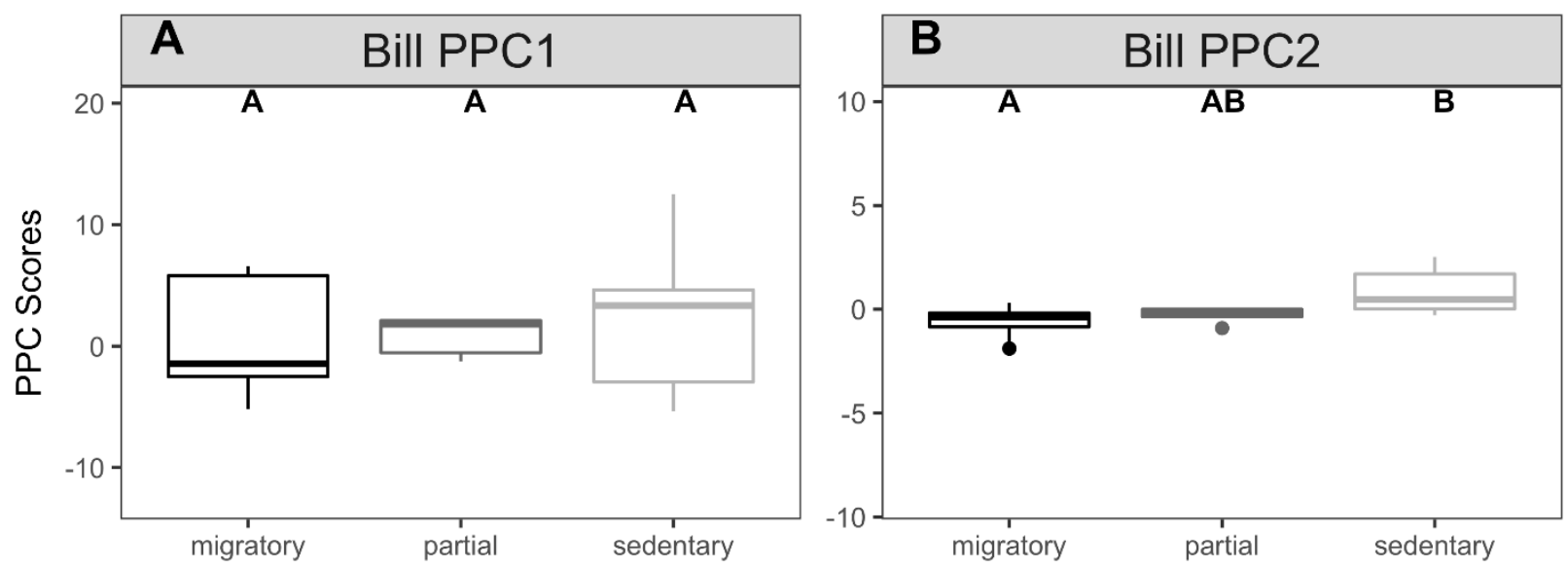

Figure 3. Phylogenetic ANOVA results comparing bill phylogenetic principal component (PPC) scores across For Peer Review migratory, partially migratory, and sedentary kingbird OTUs. Letters above each barplot show groupings resulting from post-hoc pairwise comparisons

\section{Discussion}

233 We found evidence of an association between migratory status and wing morphology in the

234 kingbirds. This corroborates the idea that migratory birds have evolved morphological features

235 that help in sustained, long-distance flight, such as longer wings (Winkler \& Leisler, 1992; Milá,

236 Wayne, \& Smith, 2008; Neto et al., 2013; Carvalho Provinciato et al., 2018). There is a strong

237 genetic component determining wing length (Böhning-Gaese \& Oberrath, 1999; Tarka et al.,

238 2010), and among migratory taxa, wing length is positively associated with migratory distance

239 (Förschler \& Bairlein, 2011; Rönn, Shafer, \& Wolf, 2016; Vágási et al., 2016; Carvalho

240 Provinciato et al., 2018). Partial migration, wherein only some individuals migrate, is thought to

241 be an evolutionary stepping-stone between sedentarism and obligate migration (Berthold, 1999;

242 Bell, 2000; Chapman et al., 2011). However, partial migration can also be sex and age-class

243 dependent, as is the case for T. melancholicus melancholicus (Jahn et al., 2010). Longer wings

244 may allow for more flexibility in altering migration speeds according to conditions experienced 
245 during migration (Hahn et al., 2016), but there may be ecological limits and trade-offs imposed

246 on wing length by other selective pressures, like shorter wings for aerial agility among arboreal

247 species (Sheard et al., 2020), for evading predators (Fernández \& Lank, 2007), or for hovering

248 flight (Marchetti, Price, \& Richman, 1995).

Our finding of differences in bill shape between migratory and sedentary taxa suggests that bill shape is a potential target of selection pressures related to migration ecology. However, our comparisons of coefficients of variation did not support intraspecific competition as a driver of diversifying selection in bill morphology among generalist migratory kingbirds. The ratio of bill length/bill width holds potential significance in foraging behaviors in other tyrannids (Botero-

254 Delgadillo \& Bayly, 2012), but our findings disagree with other research across the Tyrannidae describing generalists as having intermediate bill morphologies (Fitzpatrick, 1985). We found that sedentary taxa had longer, narrower, and shallower bills compared to migratory taxa (Figure 1B; Table 1). Previous work has shown that directional selection increasing bill length in dietary specialists may be driven by interspecific competition, including from closely related taxa

259 (Freed, Medeiros, \& Cann, 2016). Thus, other selective pressures may be acting upon the bill shape and size. For example, bill morphology has been linked with thermoregulation in dietary

261 generalists, and bill width and depth are adaptive for dissipating heat during migration for 262 improved thermoregulation (Danner \& Greenberg, 2015; Friedman et al., 2017; Danner et al., 263 2017). If convergence on bill shape is driven mainly by diet, future research integrating 264 multivariate or nonlinear bill morphometrics (e.g., hooked bills, lateral and longitudinal bill 265 curvature, bill surface area; Shao et al., 2016) with degrees of intraguild dietary specialization 266 and foraging behaviors would broaden our understanding of selection mechanisms shaping bill 267 phenotypes. been historically detectable using linear measurements of morphology alone. Divergence in bill 
270 shape between migratory and sedentary taxa may define an important component of the suite of

271 co-adaptations for migratory life histories (Bell, 2000). Morphology may be driven by selection

272 related to migration itself, such as an increased need for heat dissipation or conservation in

273 flight(see above). Alternatively, morphology may be shaped by a more complex competitive

274 landscape that affects migratory and sedentary taxa differently. In taxa occupying tropical

275 regions, like many kingbirds, the dry season is when both intra- and interspecific competition

276 increase due to 'winter food limitation' and competition with migrants returning to wintering

277 grounds, and competition with juvenile conspecifics (Hespenheide, 1975; Emlen, 1977;

278 Orejuela, Raitt, \& Álvarez, 1980; Stiles, 1980; Waide, 1980; Rappole, Ramos, \& Winker, 1989;

279 Rappole, 1995; Sherry, 2005; Danner et al., 2013). Selection may favor longer bills among

280 sedentary taxa to resolve both intra- and interspecific conflict (Table 1, Figure 3B), allowing

281 access to more temporally stable food resources in microhabitats buffered from spatial and

282 temporal environmental fluctuations (Bell, 2011).

284 combination of characteristics (e.g., Table 1, Figure 3B) support a more generalist foraging

285 strategy. For example, specific bill shapes could accommodate spatiotemporal changes in the

286 competitive landscape (Navalón et al., 2019) or provide increased stability for prey capture in

287 perch-gleaning or hover-gleaning foraging techniques (Fitzpatrick, 1985; Fitzpatrick et al., 2004;

288 Botero-Delgadillo, 2011; Botero-Delgadillo \& Bayly, 2012). The diversity of habitats that

289 migratory taxa encounter during their annual cycle may shape phenotypes in more complex

290 ways than previously thought, and techniques that incorporate more advanced characterizations

291 of morphological variation may expose novel insight into how movement life history strategies

292 shape phenotypes (e.g., Pol et al., 2009; Mallarino et al., 2011; Navalón et al., 2019; Alonso et

293 al., 2020; Medina et al., 2020). 
Aspects of both wing and bill morphology appear to have evolved in association with migratory status in kingbirds that have migratory, partially migratory, and sedentary taxa. Our results suggest that migratory status has shaped wing morphology in a widespread avian

297 genus, and that multivariate bill shape metrics may differ between sedentary and migratory

298 lineages. Thus, adaptive phenotypes may be related to migratory status in more complex ways

299 than previously understood. Assessments of the various mechanisms driving patterns in bill 300 shape (e.g., heat dissipation, foraging strategy, and competitive landscape) across a broader 301 range of taxonomic groups that differ in migration strategies would complement our refinement 302 of the morphology of migration in kingbirds.

\section{Data Availability}

305 The data underlying the work, and the R code for all statistical analyses and results shared in

306 tables and figures is available from the following public Github repository

307 (https://github.com/mmacphe/Tyrannus morphology). The voucher table and measurements of 308 all individuals will also be made available at Dryad upon publication.

\section{Acknowledgements}

311 This manuscript has been Accepted at the Biological Journal of the Linnean Society (August 02,

312 2021). We thank José Ignacio (“Nacho”) Giraldo Arango for measuring specimens, and Brenna

313 and Michael Wells, and Shelbey Hearn for their assistance measuring specimens used in this

314 study. Ben Marks, Shannon Hacket, and John Bates from the Field Museum of Natural History,

315 Bradley Millen, and Allan Baker from the Royal Ontario Museum, Gary Stiles from the Instituto 
de Ciencias Naturales, Universidad Nacional de Colombia, Jacob Saucier, Helen James, and

317 Gary Graves from the Smithsonian National Museum of Natural History, and Steven Cardiff, and

318 Van Remsen from the Louisiana State University Museum of Natural Science provided

319 assistance in accessing the specimens used in this study. Thanks to Robb Brumfield and

320 Michael Harvey for providing an early-access version of the suboscine phylogeny for our study.

321 We also thank Calandra Stanley, Caleb McMahan, the Toronto MacPhersons and the Bogotá

322 Acevedos for their special help aiding the lead author to visit collections. Travel to measure

323 specimens was supported in part from a scholar award from the James S. McDonnell

324 Foundation. Samantha Rutledge, David Vander Pluym, and Subir Shakya provided helpful

325 feedback on an earlier version of this manuscript, and we thank an anonymous reviewer and

326 Prof John A. Allen for their insightful peer review. We wish to acknowledge www.gbif.org for

327 providing the ROM database (accessed September 30, 2020) and the Field Museum database

328 (accessed October 20,2020) online that was used to validate locality data previously recorded

329 by hand. Amethys E'etessam, Clare Lister, and Trey Hendrix also helped with georeferencing

330 from locality data that was a part of this project.

$331 \quad$ Literature Cited

Albrecht GH, Gelvin BR \& Hartman SE. 1993. Ratios as a size adjustment in morphometrics. American Journal of Physical Anthropology 91: 441-468.

Alonso D, Fernández-Eslava B, Edelaar P \& Arizaga J. 2020. Morphological divergence among Spanish Common Crossbill populations and adaptations to different pine species. Ibis 162: 1279-1291.

Bartoń K. 2020. MuMIn: multi-model inference.

Bell C. 2000. Process in the evolution of bird migration and pattern in avian ecogeography. Journal of Avian Biology 31: 258-265.

Bell C. 2011. Resource buffering and the evolution of bird migration. Evolutionary Ecology 25: 91-106.

Berner D. 2011. Size correction in biology: how reliable are approaches based on (common) principal component analysis? Oecologia 166: 961-971.

Berthold P. 1999. A comprehensive theory for the evolution, control and adaptability of avian migration. Ostrich 70: 1-11.

Böhning-Gaese K \& Oberrath R. 1999. Phylogenetic effects on morphological, life-history, behavioural and ecological traits of birds. : 18. 
348

349

350

351

352

353

354

355

356

357

358

359

360

361

362

363

364

365

366

367

368

369

370

371

372

373

374

375

376

377

378

379

380

381

382

383

384

385

386

387

388

389

390

391

392

393

394

395

396

397

398

Bolnick DI, Svanbäck R, Araújo MS \& Persson L. 2007. Comparative support for the niche variation hypothesis that more generalized populations also are more heterogeneous.

Proceedings of the National Academy of Sciences 104: 10075-10079.

Botero-Delgadillo E. 2011. Cuantificando el comportamiento: Estrategias de búsqueda y ecología de forrajeo de 12 especies sintópicas de Atrapamoscas (Tyrannidae) en la Sierra Nevada de Santa Marta, Colombia. Revista Brasileira de Ornitologia 19: 343-357.

Botero-Delgadillo E \& Bayly NJ. 2012. Does morphology predict behavior? Correspondence between behavioral and morphometric data in a Tyrant-flycatcher (Tyrannidae) assemblage in the Santa Marta Mountains, Colombia. Journal of Field Ornithology 83: 329-342.

Boyle WA. 2008. Partial migration in birds: tests of three hypotheses in a tropical lekking frugivore. Journal of Animal Ecology 77: 1122-1128.

Boyle WA \& Conway CJ. 2007. Why Migrate? A Test of the Evolutionary Precursor Hypothesis. The American Naturalist 169: 344-359.

Carvalho Provinciato IC, Araújo MS \& Jahn AE. 2018. Drivers of wing shape in a widespread Neotropical bird: a dual role of sex-specific and migration-related functions. Evolutionary Ecology 32: 379-393.

Chapman BB, Brönmark C, Nilsson JÅ \& Hansson LA. 2011. The ecology and evolution of partial migration. Oikos 120: 1764-1775.

Chapman BB, Hulthén K, Brönmark C, Nilsson PA, Skov C, Hansson LA \& Brodersen J.

2015. Shape up or ship out: migratory behaviour predicts morphology across spatial scale in a freshwater fish. Journal of Animal Ecology 84: 1187-1193.

Chesser RT \& Levey DJ. 1998. Austral Migrants and the Evolution of Migration in New World Birds: Diet, Habitat, and Migration Revisited. The American Naturalist 152: 311-319.

Cintra R. 1997. Spatial Distribution and Foraging Tactics of Tyrant Flycatchers in Two Habitats in the Brazilian Amazon. Studies on Neotropical Fauna and Environment 32: 17-27.

Clegg SM \& Owens PF. 2002. The 'island rule' in birds: medium body size and its ecological explanation. Proceedings of the Royal Society of London. Series B: Biological Sciences 269: 1359-1365.

Clements JF, Schulenberg TS, Iliff MJ, Billerman SM, Fredericks TA, Sullivan BL \& Wood CL. 2019. The eBird/Clements Checklist of Birds of the World: v2019.

Cooney CR, Bright JA, Capp EJR, Chira AM, Hughes EC, Moody CJA, Nouri LO, Varley ZK \& Thomas GH. 2017. Mega-evolutionary dynamics of the adaptive radiation of birds. Nature 542: 344-347.

Cox GW. 1968. The Role of Competition in the Evolution of Migration. Evolution 22: 180-192.

Cox GW. 1985. The Evolution of Avian Migration Systems between Temperate and Tropical

Regions of the New World. The American Naturalist 126: 451-474.

Crossin GT, Hinch SG, Farrell AP, Higgs DA, Lotto AG, Oakes JD \& Healey MC. 2004.

Energetics and morphology of sockeye salmon: effects of upriver migratory distance and elevation. Journal of Fish Biology 65: 788-810.

Danner RM, Greenberg RS, Danner JE, Kirkpatrick LT \& Walters JR. 2013. Experimental support for food limitation of a short-distance migratory bird wintering in the temperate zone. Ecology 94: 2803-2816.

Danner RM, Gulson-Castillo ER, James HF, Dzielski SA, Frank DC III, Sibbald ET \& Winkler DW. 2017. Habitat-specific divergence of air conditioning structures in bird bills. The Auk 134: 65-75.

Danner RM \& Greenberg R. 2015. A critical season approach to Allen's rule: Bill size declines with winter temperature in a cold temperate environment. Journal of Biogeography 42: 114-120. Emlen JT. 1977. Land Bird Communities of Grand Bahama Island: The Structure and Dynamics of an Avifauna. Ornithological Monographs: iii-129.

Felice RN, Tobias JA, Pigot AL \& Goswami A. 2019. Dietary niche and the evolution of cranial morphology in birds. Proceedings of the Royal Society B: Biological Sciences 286: 
399

400

401

402

403

404

405

406

407

408

409

410

411

412

413

414

415

416

417

418

419

420

421

422

423

424

425

426

427

428

429

430

431

432

433

434

435

436

437

438

439

440

441

442

443

444

445

446

447

448

449

20182677.

Fernández G \& Lank DB. 2007. Variation in the Wing Morphology of Western Sandpipers (Calidris Mauri) in Relation to Sex, Age Class, and Annual Cycle. The Auk 124: 1037-1046. Fiedler W. 2005. Ecomorphology of the External Flight Apparatus of Blackcaps ( Sylvia atricapilla ) with Different Migration Behavior. Annals of the New York Academy of Sciences 1046: 253-63.

FitzJohn RG. 2012. Diversitree: comparative phylogenetic analyses of diversification in R. Methods in Ecology and Evolution 3: 1084-1092.

Fitzpatrick JW. 1981. Search strategies of tyrant flycatchers. Animal Behaviour 29: 810-821. Fitzpatrick JW. 1985. Form, foraging behavior, and adaptive radiation in the Tyrannidae BT Neo-Tropical Ornithology Ornithological Monographs No. 26. In: Neo-Tropical Ornithology Ornithological Monographs No. 26., 447-470.

Fitzpatrick JW, Bates JM, Bostwick KS, Caballero IC, Clock BM, Farnsworth A, Hosner PA, Joseph L, Langham GM \& Lebbin DJ. 2004. Family Tyrannidae (tyrant-flycatchers). Handbook of the birds of the world 9: 170-462.

Fitzpatrick W \& Schauensee D. 1980. Foraging behavior of Tyrant flycatchers. : 43-57. Förschler MI \& Bairlein F. 2011. Morphological Shifts of the External Flight Apparatus across the Range of a Passerine (Northern Wheatear) with Diverging Migratory Behaviour. PLOS ONE 6: e18732.

Freed LA, Medeiros MCI \& Cann RL. 2016. Multiple Reversals of Bill Length over 1.7 Million Years in a Hawaiian Bird Lineage. The American Naturalist 187: 363-371.

Friedman NR, Harmáčková L, Economo EP \& Remeš V. 2017. Smaller beaks for colder winters: Thermoregulation drives beak size evolution in Australasian songbirds. Evolution 71: 2120-2129.

Gabriel V de A \& Pizo MA. 2005. Foraging behavior of tyrant flycatchers (Aves, Tyrannidae) in Brazil. Revista Brasileira de Zoologia 22: 1072-1077.

Garland T, Dickerman AW, Janis CM \& Jones JA. 1993. phylogenetic analysis of covariance by computer simulation. Systematic Biology 42: 265-292.

Gómez C, Tenorio EA, Montoya P \& Cadena CD. 2016. Niche-tracking migrants and nicheswitching residents: evolution of climatic niches in New World warblers (Parulidae). Proceedings of the Royal Society B: Biological Sciences 283: 20152458.

Gómez-Bahamón V, Márquez R, Jahn AE, Miyaki CY, Tuero DT, Laverde-R O, Restrepo S \& Cadena CD. 2020a. Speciation Associated with Shifts in Migratory Behavior in an Avian Radiation. Current Biology 30: 1312-1321.e6.

Gómez-Bahamón V, Tuero DT, Castaño MI, Jahn AE, Bates JM \& Clark CJ. 2020b. Sonations in Migratory and Non-migratory Fork-tailed Flycatchers ( Tyrannus savana ). Integrative and Comparative Biology 60: 1147-1159.

Guillerme T \& Healy K. 2020. mulTree: performs MCMCgImm on Multiple Phylogenetic Trees. Haberman K, MacKenzie DI \& Rising JD. 1991. Geographic Variation in the Gray Kingbird (Variación geográfica en Tyrannus dominicensis). Journal of Field Ornithology 62: 117-131. Hahn S, Korner-Nievergelt F, Emmenegger T, Amrhein V, Csörgő T, Gursoy A, Ilieva M, Kverek P, Pérez-Tris J, Pirrello S, Zehtindjiev P \& Salewski V. 2016. Longer wings for faster springs - wing length relates to spring phenology in a long-distance migrant across its range. Ecology and Evolution 6: 68-77.

Harvey M, Bravo G, Claramunt S, Cuervo A, Derryberry G, Battilana J, Seeholzer G, McKay JS, O'Meara BC, Faircloth BC, Edwards S, Pérez-Emán J, Moyle RG, Sheldon FH, Aleixo A, Smith BT, Chesser RT, Silveira LF, Cracraft J, Brumfield RT \& Derryberry EP. 2020. The evolution of a tropical biodiversity hotspot. Science 370: 1343-1348.

Herrera CM. 1978. Ecological Correlates of Residence and Non-Residence in a Mediterranean Passerine Bird Community. Journal of Animal Ecology 47: 871-890.

Hespenheide HA. 1975. Selective Predation by Two Swifts and a Swallow in Central America. 
Ibis 117: 82-99.

Hromada M \& Tryjanowski P. 2003. Animals of different phenotype differentially utilise dietary niche - the case of the Great Grey Shrike Lanius excubitor. 80: 8.

Jahn AE, Levey DJ, Mamani AM, Saldias M, Alcoba A, Ledezma MJ, Flores B, Vidoz JQ \& Hilarion F. 2010a. Seasonal differences in rainfall, food availability, and the foraging behavior of Tropical Kingbirds in the southern Amazon Basin. Journal of Field Ornithology 81: 340-348. Jahn AE, Levey DJ, Hostetler JA \& Mamani AM. 2010b. Determinants of partial bird migration in the Amazon Basin. Journal of Animal Ecology 79: 983-992.

Jahn AE \& Tuero DT. 2020. Fork-tailed Flycatcher (Tyrannus savana). Birds of the World. Johansson F, Söderquist M \& Bokma F. 2009. Insect wing shape evolution: independent effects of migratory and mate guarding flight on dragonfly wings. Biological Journal of the Linnean Society 97: 362-372. Kipp F. 1942. Über Flügelbau und Wanderzug der Vögel. Biologisches Zentralblatt 62: 289_ 299.

464 Kipp FA. 1958. Zur geschichte des Vogelzuges auf der grundlage der Flügelanpassungen.

465 Vogelwarte 19: 233-242.

466 Knudsen R, Siwertsson A, Adams CE, Garduño-Paz M, Newton J \& Amundsen PA. 2011. pressures. Evolutionary Ecology 25: 589-604.

Lack D. 1971. Ecological isolation in birds.

Leisler B. 1990. Selection and Use of Habitat of Wintering Migrants. In: Gwinner E, ed. Bird Migration. Berlin, Heidelberg: Springer Berlin Heidelberg, 156-174. Availability and Movement Patterns in Neotropical Landbirds. The American Naturalist 140: 447-476.

Lindström A \& Piersma T. 1993. Mass changes in migrating birds: the evidence for fat and protein storage re-examined. Ibis 135: 70-78.

Lockwood R, Swaddle JP \& Rayner JMV. 1998. Avian Wingtip Shape Reconsidered: Wingtip Shape Indices and Morphological Adaptations to Migration. Journal of Avian Biology 29: 273292.

Mallarino R, Grant PR, Grant BR, Herrel A, Kuo WP \& Abzhanov A. 2011. Two developmental modules establish 3D beak-shape variation in Darwin's finches. Proceedings of the National Academy of Sciences 108: 4057-4062.

Marchetti K, Price T \& Richman A. 1995. Correlates of Wing Morphology with Foraging Behaviour and Migration Distance in the Correlates of wing morphology with foraging behaviour and migration distance in the genus Phylloscopus. Journal of Avian Biology 26: 177-181. McCoy MW, Bolker BM, Osenberg CW, Miner BG \& Vonesh JR. 2006. Size correction: comparing morphological traits among populations and environments. Oecologia 148: 547-554. Medina JJ, Maley JM, Sannapareddy S, Medina NN, Gilman CM \& McCormack JE. 2020. A rapid and cost-effective pipeline for digitization of museum specimens with 3D photogrammetry. PLOS ONE 15: e0236417.

Milá B, Wayne RK \& Smith TB. 2008. Ecomorphology of Migratory and Sedentary Populations of the Yellow-Rumped Warbler (Dendroica Coronata). The Condor 110: 335-344.

Minias P, Meissner W, Włodarczyk R, Ożarowska A, Piasecka A, Kaczmarek K \& Janiszewski T. 2015. Wing shape and migration in shorebirds: a comparative study. Ibis 157: 528-535.

Mobley JA. 2002. Molecular phylogenetics and the evolution of nest building in kingbirds and their allies (Aves: Tyrannidae). University of California, Berkeley.

Mobley JA \& de Juana E. 2020. Loggerhead Kingbird (Tyrannus caudifasciatus). Birds of the World.

500 Mönkkönen M. 1995. Do migrant birds have more pointed wings?: A comparative study. 
501

502

503

504

505

506

507

508

509

510

511

512

513

514

515

516

517

518

519

520

521

522

523

524

525

526

527

528

529

530

531

532

533

534

535

536

537

538

539

540

541

542

543

544

545

546

547

548

549

550

551

Evolutionary Ecology 9: 520-528.

Moreau RE. 1952. The Place of Africa in the Palaearctic Migration System. Journal of Animal Ecology 21: 250-271.

Morse DH. 1971. The Insectivorous Bird as an Adaptive Strategy. Annual Review of Ecology and Systematics 2: 177-200.

Mulvihill RS \& Chandler CR. 1990. The Relationship between Wing Shape and Differential Migration in the Dark-Eyed Junco. The Auk 107: 490-499.

Murphy MT. 2007. A Cautionary Tale: Cryptic Sexual Size Dimorphism in a Socially Monogamous Passerine. The Auk 124: 515-525.

Nations JA, Heaney LR, Demos TC, Achmadi AS, Rowe KC \& Esselstyn JA. 2019. A simple skeletal measurement effectively predicts climbing behaviour in a diverse clade of small mammals. Biological Journal of the Linnean Society 128: 323-336.

Navalón G, Bright JA, Marugán-Lobón J \& Rayfield EJ. 2019. The evolutionary relationship among beak shape, mechanical advantage, and feeding ecology in modern birds*. Evolution 73: 422-435.

Neto JM, Gordinho L, Belda EJ, Marín M, Monrós JS, Fearon P \& Crates R. 2013.

Phenotypic Divergence among West European Populations of Reed Bunting Emberiza schoeniclus: The Effects of Migratory and Foraging Behaviours. PLOS ONE 8: e63248. Norberg UM. 1990. Vertebrate flight: mechanics, physiology, morphology, ecology and evolution. Berlin: Springer.

Norberg UM. 1995. WING DESIGN AND MIGRATORY FLIGHT. Israel Journal of Ecology and Evolution 41: 297-305.

Orejuela JE, Raitt RJ \& Álvarez H. 1980. Differential use by North American migrants of three types of Colombian forests: 253-264 (en) KEAST, A. \& MORTON, ES (eds.). Migrant Birds in

the Neotropics: Ecology, Behavior, Distribution and Conservation. Smithsonian Institution Press. Washington DC, USA.

Pennycuick C. 2008. The membrane wings of bats and pterosaurs Modelling the Flying Bird ed CJ Pennycuick.

Pérez-Tris J \& Tellería JL. 2001. Age-related variation in wing shape of migratory and sedentary Blackcaps Sylvia atricapilla. Journal of Avian Biology 32: 207-213.

Pol MVD, Ens BJ, Oosterbeek K, Brouwer L, Verhulst S, Tinbergen JM, Rutten AL \& Jong MD. 2009. Oystercatchers' Bill Shapes as a Proxy for Diet Specialization: More Differentiation than Meets the Eye. Ardea 97: 335-347.

Pyle P, Howell SNG, Institute for Bird Populations, \& Point Reyes Bird Observatory. 1997. Identification guide to North American birds: a compendium of information on identifying, ageing, and sexing 'near-passerines' and passerines in the hand. Part I, Part I,. Bolinas, Calif.: Slate Creek Press.

R Core Team. 2020. R: A Language and Environment for Statistical Computing (4.0.

3)[Computer software]. R Foundation for Statistical Computing. Retrieved from http://www. Rproje ....

Rappole JH. 1995. The ecology of migrant birds: a neotropical perspective. Washington; London: Smithsonian institution Press.

Rappole JH, Ramos MA \& Winker K. 1989. Wintering Wood Thrush Movements and Mortality in Southern Veracruz. The Auk 106: 402-410.

Rayner JMV. 1988. The evolution of vertebrate flight. Biological Journal of the Linnean Society 34: 269-287.

Reaney AM, Bouchenak-Khelladi Y, Tobias JA \& Abzhanov A. 2020. Ecological and morphological determinants of evolutionary diversification in Darwin's finches and their relatives. Ecology and Evolution 10: 14020-14032.

Regosin JV \& Pruett-Jones S. 2001. Sexual Selection and Tail-Length Dimorphism in ScissorTailed Flycatchers. The Auk 118: 167-175. 
552

553

554

555

556

557

558

559

560

561

562

563

564

565

566

567

568

569

570

571

572

573

574

575

576

577

578

579

580

581

582

583

584

585

586

587

588

589

590

591

592

593

594

595

596

597

598

599

600

601

602

Revell LJ. 2009. Size-Correction and Principal Components for Interspecific Comparative Studies. Evolution 63: 3258-3268.

Revell LJ. 2012. phytools: an R package for phylogenetic comparative biology (and other things). Methods in Ecology and Evolution 3: 217-223.

Rising JD \& Somers KM. 1989. The Measurement of Overall Body Size in Birds. The Auk 106: 666-674.

Rönn JAC von, Shafer ABA \& Wolf JBW. 2016. Disruptive selection without genome-wide evolution across a migratory divide. Molecular Ecology 25: 2529-2541.

Senar JC \& Pascual J. 1997. Keel and tarsus length may provide a good predictor of avian body size. Ardea 85.

Shao S, Quan Q, Cai T, Song G, Qu Y \& Lei F. 2016. Evolution of body morphology and beak shape revealed by a morphometric analysis of 14 Paridae species. Frontiers in Zoology 13: 30.

Sheard C, Neate-Clegg MHC, Alioravainen N, Jones SEI, Vincent C, MacGregor HEA, Bregman TP, Claramunt S \& Tobias JA. 2020. Ecological drivers of global gradients in avian dispersal inferred from wing morphology. Nature Communications 11: 2463.

Sherry TW. 1984. Comparative Dietary Ecology of Sympatric, Insectivorous Neotropical Flycatchers (Tyrannidae). Ecological Monographs 54: 313-338.

SHERRY TW. 2005. Does winter food limit populations of migratory birds? Birds of two worlds: the ecology and evolution of migration: 414-425.

Snow DW. 1953. Systematics and comparative ecology of the genus Parus in the Palaearctic region.

Snow DW. 1954. The habitats of Eurasian tits (Parus spp.). Ibis 96: 565-585.

Stiles FG. 1980. Evolutionary implications of habitat relations between permanent and winter resident landbirds in Costa Rica. Migrant Birds in the Neotropics (A. Keast and ES Morton, Eds.) Smithsonian Institution Press, Washington DC: 421-435.

Svanbäck R \& Schluter D. 2012. Niche Specialization Influences Adaptive Phenotypic Plasticity in the Threespine Stickleback. The American Naturalist 180: 50-59.

Swanson MT, Oliveros CH \& Esselstyn JA. 2019. A phylogenomic rodent tree reveals the repeated evolution of masseter architectures. Proceedings of the Royal Society B: Biological Sciences 286: 20190672.

Tarka M, Ákesson M, Beraldi D, Hernández-Sánchez J, Hasselquist D, Bensch S \& Hansson B. 2010. A strong quantitative trait locus for wing length on chromosome 2 in a wild population of great reed warblers. Proceedings of the Royal Society B: Biological Sciences 277: 2361-2369.

Tellería LJ, Blázquez M, De La Hera I \& Pérez-Tris J. 2013. Migratory and resident Blackcaps Sylvia atricapilla wintering in southern Spain show no resource partitioning. Ibis 155: 750-761.

Tellería JL \& Carbonell R. 1999. Morphometric Variation of Five Iberian Blackcap Sylvia atricapilla Populations. Journal of Avian Biology 30: 63-71.

Thiollay JM. 1988. Comparative Foraging Success of Insectivorous Birds in Tropical and Temperate Forests: Ecological Implications. Oikos 53: 17-30.

Vágási CI, Pap PL, Vincze O, Osváth G, Erritzøe J \& Møller AP. 2016. Morphological Adaptations to Migration in Birds. Evolutionary Biology 43: 48-59.

Van Dijk A, Nakamura G, Rodrigues AV, Maestri R \& Duarte L. 2021. Imprints of tropical niche conservatism and historical dispersal in the radiation of Tyrannidae (Aves:

Passeriformes). Biological Journal of the Linnean Society.

Van Valen L. 1965. Morphological Variation and Width of Ecological Niche. The Amercian Naturalist 99: 377-390.

Voelker G. 2001. Morphological correlates of migratory distance and flight display in the avian genus Anthus. Biological Journal of the Linnean Society 73: 425-435.

Waide RB. 1980. Resource partitioning between migrant and resident birds: the use of irregular resources. Migrant birds in the Neotropics: ecology, behavior, distribution, and conservation: 
337-352.

Wang X \& Clarke JA. 2015. The evolution of avian wing shape and previously unrecognized trends in covert feathering. Proceedings of the Royal Society B: Biological Sciences 282: 20151935.

Wiedenfeld DA. 1991. Geographical Morphology of Male Yellow Warblers. The Condor 93: 712-723.

610 Ecological Monographs 44: 153-169.

611 Wilson EO. 1961. The Nature of the Taxon Cycle in the Melanesian Ant Fauna. The American

612 Naturalist 95: 169-193.

613 Winkler H \& Leisler B. 1992. On the ecomorphology of migrants. Ibis 134: 21-28.

614 Winquist T \& Lemon RE. 1994. Sexual Selection and Exaggerated Male Tail Length in Birds.

615 The American Naturalist 143: 95-116.

616 Závorka L, Larranaga N, Lovén Wallerius M, Näslund J, Koeck B, Wengström N,

617 Cucherousset $\mathbf{J}$ \& Johnsson Jl. 2020. Within-stream phenotypic divergence in head shape of 618 brown trout associated with invasive brook trout. Biological Journal of the Linnean Society 129:

$619 \quad 347-355$.

\section{Supporting Information}

621 Supporting Information 1 - Supplementary Results

622 Supporting Information 2 - Image J protocol for measuring long Tyrannus tail lengths

623 Supporting Information 3 - Sex-specific results: means for each morphometric, phylogenetic

624 principal components analysis (PPCA), and phylogenetic ANOVA 